\title{
O paradigma dogmático da ciência jurídica nos manuais de ensino do direito*
}

\section{The dogmatic paradigm of legal science in the manuals of law education}

Samyra Naspolini Sanches ${ }^{1}$ Samantha Ribeiro Meyer-Pflug ${ }^{2}$

* Artigo recebido em maio de 2013.

Aceito para publicação em junho de 2013.

1 Doutora em Direito pela PUC/SP, Professora e Pesquisadora do Centro de Pesquisa em Direito da UNINOVE, Professora Colaboradora do Mestrado em Direito do UNIVEM de Marília.

2 Doutora e Mestre em Direito pela PUC/SP, Coordenadora e Professora do Curso de Direito e do mestrado em Direito da UNINOVE, membro do Conselho Superior de Direito da Federação do Comércio/FECOMERCIO/SP e do Conselho Superior de Estudos Avançados da FIESP. Advogada 


\section{Introdução}

O presente artigo tem por objeto os conceitos acerca do Direito e da Ciência Jurídica encontrados nas principais referências e bibliografias utilizadas pelos docentes nas diversas disciplinas dogmáticas do Curso de Direito.

Visa-se verificar qual a concepção de Direito está sendo ensinada nas Faculdades de Direito, sendo que a hipótese da pesquisa é a de que as Faculdades reproduzem o paradigma dogmático de Ciência Jurídica e o senso comum teórico dos juristas, uma vez que o estudo dos diversos ramos do Direito se limita ao estudo das normas contidas nos Códigos, que compõem inclusive o próprio conteúdo programático dos planos de ensino, sem qualquer reflexão ou crítica.

O paradigma epistemológico do Ensino Jurídico que durante muitos anos perdurou e ainda perdura nas faculdades de direito não se mostra mais capaz para formar bacharéis em Direito aptos a lidarem com êxito aos desafios que lhe impõe a vida acadêmica e a vida profissional.

A própria evolução da sociedade e as inovações tecnológicas impõem uma concepção mais dinâmica do Direito, exige-se do bacharel em direito, cada vez mais, a capacidade de criar soluções para esse mundo globalizado e em constante mutação.

No entanto, a grade curricular dos cursos de Direito baseadas num dogmatismo jurídico, que se limita ao estudo apenas das normas jurídicas, do direito positivo, não se apresenta capaz de formar um bacharel em direito apto a enfrentar os desafios de um mundo globalizado.

As críticas dirigidas ao paradigma epistemológico do Ensino Jurídico brasileiro têm considerado este problema como um problema de estrutura que vem acompanhado de uma série de outros problemas funcionais e operacionais que são identificados no Ensino Jurídico desde os seus primórdios.

A reprodução do paradigma dogmático da $\mathrm{Ci}$ ência Jurídica e o senso comum teórico dos juristas reproduzidos pelas Faculdades de Direito, não propicia ao aluno de direito o desenvolvimento amplo de suas capacidades e habilidades.

Para atingir seus objetivos, o artigo em seu primei- tado pelo Ensino Jurídico Brasileiro e no segundo item aborda o papel dos Manuais de Direito na reprodução deste paradigma.

A pesquisa realizada utilizou-se do metido indutivo e como técnica de pesquisa a bibliográfica e documental.

\section{Reflexões sobre o paradigma epistemológico do ensino jurídico brasileiro}

A metodologia de ensinar o Direito com base em Compêndios ou Manuais é uma tradição herdada da Universidade de Coimbra, a qual adotou esta metodologia desde a reforma pombalina. Verifica-se que desde a sua criação os cursos de direito sempre conferiram maior relevância a retórica e a forma do que ao conteúdo e a reflexão. ${ }^{3}$

A Ciência Jurídica consolidou o seu paradigma dogmático, positivista, a partir da concepção do Direito como norma jurídica. Assim sendo, dentro desta concepção, estudar o Direito irá significar estudar as normas jurídicas, principalmente as cristalizadas nos códigos. Adotou-se uma postura positivista. Há uma valorização do estudo das normas jurídicas e um desprezo aos demais elementos que compõem o Direito.

O conteúdo restrito dos cursos jurídicos não parece ser uma característica somente do Brasil, pois segundo o depoimento de Roberto Mangabeira Unger

o conteúdo do ensino jurídico tem continuado
a ser, na maior parte do mundo, o que sempre
foi: um escolasticismo doutrinário e exegético,
com pouco valor prático para a advocacia e me-
nor valor ainda para o entendimento e o mane-
jamento dos pactos nacionais de poder. ${ }^{4}$

Esta forma de ver o Direito será denominada no presente artigo de paradigma epistemológico e a sua influência pode ser identificada fortemente em nível da estrutura acadêmica. Assevera Horácio Wanderlei Rodrigues que:

3 Cf. FONSECA, Ricardo Marcelo. Introdução teórica à história do Direito. Rio de Janeiro: Livraria Freitas Bastos, 2010. p 18.

4 UNGER, Roberto Mangabeira. Uma nova faculdade de direito no Brasil. Paper apresentado na Fundação Getúlio Vargas como parecer sobre a criação da Escola de Direito de São Paulo/FGV - EDESP, 2001. p 3. 
A concepção do ensino vigente, que é a da educação tradicional, tem fortes vínculos com o positivismo e a sua concepção de ciência e verdade.[...] No que se refere à metodologia de ensino e ao currículo, ambos estão fortemente marcados pelo positivismo, a primeira através da técnica do código comentado e o segundo pela ênfase normativista. ${ }^{5}$

Lyra Filho já alertava para este grande equívoco epistemológico, nos seguintes termos::

\begin{abstract}
[...] o importante a destacar é outra coisa: parece-me que existe um equívoco generalizado e estrutural na própria concepção do direito que se ensina. Daí é que partem os problemas; e desta maneira, o esforço deste ou daquele não chega a remediar a situação globalmente falsa. É preciso chegar à fonte, e não às consequências [...] temos de repensar o ensino jurídico, a partir de sua base: o que é Direito, para que se possa ensiná-lo? Noutras palavras, não é a reforma de currículos e programas que resolveria a questão. As alterações que se limitam aos corolários programáticos ou curriculares deixam intocado o núcleo e pressuposto errôneo. ${ }^{6}$
\end{abstract}

Assim, o Direito é identificado com a norma jurídica estatal e a sua ciência com uma simples técnica de controle social. Por estes motivos, o estudo dos diversos ramos do Direito, nas disciplinas distribuídas ao longo da grade curricular dos cursos jurídicos, limita-se ao estudo dos Códigos, que compõem, inclusive, o próprio conteúdo programático dos planos de ensino que se restringem a transcrever os índices dos códigos.

Todavia, a compreensão do Direito perpassa a sua construção histórica, deve ser ele entendido como um fenômeno político, cultural e social e não apenas jurídico.

A concepção do direito adotada pelas faculdades de direito é extremamente formalista e o ensino é excessivamente dogmático. ${ }^{7}$ Limita-se o aprendizado do direito ao conhecimento descritivo e sistemático das normas jurídicas, ou seja, do ordenamento jurídico, bem como de seus institutos. Não se vislumbra, salvo exceções, nenhuma preocupação com a necessidade formar competências

5 RODRIGUES, Horácio Wanderlei. Novo currículo mínimo dos cursos jurídicos. São Paulo: RT, 1995. p. 16

6 LYRA FILHO, Roberto. O direito que se ensina errado. Brasília: UnB. Centro Acadêmico de Direito, 1980. p. 6.

7 Cf. FARIA, Adriana Ancona de. "A formação de novas competências: articulação da grade curricular e de metodologias participativas no curso de Direito da GV. In: SILVEIRA, Vladmir Oliveira da; COUTO, Monica Bonetti; SANCHES, Samyra Haydêe Dal Farra Naspolini (Org.). Educação Jurídica. São Paulo: Saraiva, 2013. p. 29. e desenvolver habilidades no bacharel em direito no sentido propiciar a ele o conhecimento necessário para atuar numa sociedade globalizada e dinâmica.

Nesse contexto o emprego de manuais nos Cursos de Direito torna-se presença obrigatória, pois essas obras jurídicas se limitam a reproduzir o conteúdo dos Códigos, sem suscitar uma análise critica por parte do aluno.

\section{0 papel dos manuais de direito no ensino jurídico}

Os manuais irão transmitir uma informação de caráter meramente instrumental, o conjunto dos dogmas do direito, que passam a ideia da existência de um sistema normativo completo, coerente e sem lacunas, neutro e objetivo na melhor tradição kelseniana, ${ }^{8}$ como se constituíssem "autênticas verdades reveladas, diante das quais ao aluno não restaria outra opção senão a de aceitá-las do modo mais acrítico possível" 9 .

Não se verifica nesses manuais qualquer visão crítica sobre os temas jurídicos abordados, pelo contrário seu conteúdo repele qualquer análise crítica ou dialética.

A Dogmática Jurídica apresenta a legislação como objeto único do Direito e assim o dogmatismo, que é dominante na ciência e na Filosofia do Direito, vai servir de base ao dogmatismo do Ensino Jurídico, o qual, por seu turno, "retroalimenta e conserva o primeiro, num autêntico círculo vicioso, dentro de um sistema de pensamento extraordinariamente fechado." 10

O domínio desse paradigma pode ser claramente vislumbrado no Ensino Jurídico brasileiro, no qual, por meio de várias reformas curriculares, foram sendo cada vez mais acrescentadas disciplinas profissionalizantes que levam a mesma denominação dos códigos aos quais dizem respeito. Assim temos o Direito Civil, que irá estudar o Código Civil, o Direito Penal, que irá estudar o Código Penal, o Direito Comercial, que irá estudar o Código Comercial, o Direito Processual Civil, que irá estudar o Código de Processo Civil, etc. Tudo isto sem qualquer

\footnotetext{
8 FARIA, José Eduardo. A reforma do ensino jurídico. Porto Alegre: Sergio Antonio Fabris Editor, 1987. p. 45.

9 MARQUES NETO, Agostinho Ramalho. A ciência do direito: conceito, objeto, método. 2. ed. Rio de Janeiro: 2001. p. 210.

${ }^{10}$ MARQUES NETO, Agostinho Ramalho. A ciência do direito: conceito, objeto, método. 2. ed. Rio de Janeiro: 2001. p. 212.
} 
questionamento acerca da política de produção das normas, os efeitos da sua aplicação e principalmente sobre a sua adequação em um dado contexto socioeconômico.

Constata-se que ainda prevalece no sistema brasileiro o modelo napoleônico de universidade, no qual há uma nítida fragmentação entre teoria e prática. Valorizam-se apenas as aulas expositivas, as denominadas "aulas conferências", nas quais os professores discorrem sobre o conteúdo das disciplinas, comentam os códigos e os alunos passivamente absorvem o conteúdo, ou melhor, memorizam o conteúdo. ${ }^{11}$

Para as disciplinas ditas fundamentais, ou propedêuticas, caberia a tarefa de abordar os aspectos filosóficos, científicos, políticos e sociológicos do Direito, porém estes, "quando não são simplesmente negligenciados, são apresentados ao aluno, via de regra, dentro de um dogmatismo normativista que o induz à crença de que o Direito se reduz às leis." ${ }^{2} \mathrm{Na}$ maioria das Faculdades de Direito não há um corpo docente qualificado para lecionar de forma adequada estas disciplinas.

Assim, o mundo é apresentado ao estudante de Direito "pela mediação dos textos legais e a norma jurídica, que é meio de controle de conduta em dada sociedade, editada por um poder que pode ser legítimo, ou ilegítimo, torna-se ela própria um fim em si mesma”. ${ }^{13}$

A metodologia de ensino, também na maioria dos casos, consiste na repetição e leitura dos Manuais, gerando um total desestimulo à frequência às aulas. $\mathrm{Na}$ ocasião da avaliação o aluno decora as verdades contidas nos manuais e as repete na prova. Não há qualquer reflexão sobre o conteúdo jurídico ministrado. Pelo contrário as avaliações formuladas nas faculdades de direito repelem qualquer reflexão por parte do aluno.

Cumpre registrar, nesse sentido, um levantamento realizado por Melo Filho em 2009, segundo o qual ses-

${ }^{11}$ Cf. PAGANI, Juliana Ferrari de Oliveira."A pós-graduação stritco sensu em Direito no Brasil: a formação dos professores das disciplinas pedagógicas oferecidas em seus programas" In.: SILVEIRA, Vladmir Oliveira da; COUTO, Monica Bonetti; SANCHES, Samyra Haydêe Dal Farra Naspolini (Org.). Educação jurídica. São Paulo: Saraiva, 2013. p. 258

${ }^{12}$ MARQUES NETO, Agostinho Ramalho. A ciência do direito: conceito, objeto, método. 2 ed. Rio de Janeiro: 2001. p.211.

${ }^{13}$ LÔBO, Paulo Luiz Neto et al. Uma Cartografia dos Problemas. In: $O A B$ Ensino Jurídico: diagnósticos, perspectivas e propostas. Brasília: Conselho Federal da OAB, 1996 p. 23. senta e sete por cento dos alunos de direito limitam o seu estudo a um livro "manual" por disciplina, na maioria das vezes, de indicação do professor e sessenta e três por cento dos docentes se utilizam apenas da aula expositiva como técnica em sala de aula. Nesse sentido preleciona Celso Campilongo:

Como o docente e os alunos não vão além dos manuais - sempre ressalvando as exceções -, estes banalizam o limite da mediocridade consentido pelas práticas acadêmicas. Nossos manuais mais divulgados, em praticamente todas as áreas, foram escritos há mais de 15 anos. Muitas vezes são parcos, quando não omissos ou totalmente desatualizados, quanto às referências bibliográficas. A menção a correntes diversas ou interpretações divergentes quase não existe. Por fim, desencorajam a busca de outras fontes. São, de fato, o porto seguro dos acomodados. ${ }^{14}$

Comentando o assunto, Lênio Strek entende ser possível afirmar que no nosso país se estabeleceu uma "cultura jurídica standard", na qual os manuais jurídicos oferecem ao jurista na prática de sua profissão "soluções e conceitos lexicográficos", uma coletânea de "prêts-à-porter significativos", que irão compor o conteúdo de suas petições, pareceres e sentenças "com ementas jurisprudenciais que são citadas, no mais das vezes, de forma descontextualizada." ${ }^{15}$

Em crítica contundente aos Manuais, Tércio Sampaio Ferraz Junior resume as ideias até aqui apresentadas:

Manuais de direito no Brasil são em regra, dogmáticos e de baixa densidade em matéria de problematização científica. Na maioria são meramente classificatórios, repetem, resumem (mal) velhas teorias, nunca ensinam o estudante a pensar juridicamente, sugerindo, ao contrário, que o pensamento jurídico se resume em citar autores, repetir textos normativos e chegar a conclusões baseadas em autoridade da jurisprudência. Os programas espelham os manuais. E os métodos raramente vão além de uma aula expositiva que mal repete o manual. ${ }^{16}$

Na sequencia e com o objetivo de ilustrar as afirmações feitas com relação ao conteúdo dos manuais, se-

${ }^{14}$ CAMPILONGO, Celso. OAB - Ensino Jurídico. In: OAB Ensino Jurídico: diagnósticos, perspectivas e propostas. Brasília: Conselho Federal da OAB, 1996 p. 86.

15 STRECK, Lenio Luiz. Hermenêutica jurídica e $(m)$ crise: uma exploração hermenêutica da construção do Direito. 2 ed. Porto Alegre: Livraria do Advogado. 2000. p. 73.

16 FERRAZ JR, Tércio Sampaio. OAB: Ensino Jurídico. In: $O A B$ Ensino Jurídico: diagnósticos, perspectivas e propostas. Brasília: Conselho Federal da OAB, 1996. p. 284. 
guem algumas citações extraídas de vários manuais que orientam as disciplinas dogmáticas nas Faculdades de Direito nos quatro cantos de nosso país. O critério de escolha dos autores foi, exatamente, o da notoriedade e do alto grau de adoção pelos alunos e professores de Direito.

Na definição do que seria o Direito Penal no primeiro volume de sua obra, com a finalidade de introduzir o aluno na disciplina, encontramos a seguinte afirmação do Professor Damásio de Jesus:

[...] definimos o Direito Penal como o conjunto de normas que ligam ao crime, como fato, a pena como consequência, e disciplinam também as relações jurídicas daí derivadas, para estabelecer a aplicabilidade das medidas de segurança e a tutela do direito de liberdade em face do poder de punir do Estado. ${ }^{17}$ (grifo nosso)

Em outra passagem de sua obra, Damásio de Jesus afirma que o Direito Penal "como ciência jurídica, tem natureza dogmática, uma vez que as suas manifestações têm por base o direito positivo. Expõe o seu sistema através de normas jurídicas, exigindo o seu cumprimento sem reservas." ${ }^{18}$ (grifo nosso)

Por ter natureza dogmática, seu método será o “técnico-jurídico, que permite a 'pronta realizabilidade do Direito"', pois, para o autor, “o Direito existe para realizar-se, pois a sua realização é a vida e a verdade do Direito. Chama-se método técnico-jurídico o conjunto de meios que servem para a efetivação desse objetivo." ${ }^{19}$

Já Magalhães Noronha outro renomado penalista, muito lido e utilizado nas Faculdades de Direito, conceitua o Direito Penal exatamente da mesma forma:

Resumidamente: direito penal é o conjunto de
normas jurídicas que regulam o poder puniti-
vo do Estado, tendo em vista os fatos de natu-
reza criminal e as medidas aplicáveis a quem os
pratica. ${ }^{20}$ (grifo nosso)

A concepção epistemológica sobre a ciência jurídico-penal também é a mesma: "tem o direito penal caráter dogmático, não se compadecendo com tendências

${ }_{17}$ JESUS, Damásio E. de. Direito penal. 22 ed. São Paulo: Saraiva, 1999. v. 1, p 5.

${ }^{18}$ JESUS, Damásio E. de. Direito Penal. 19 ed. São Paulo: Saraiva, 1999. v. 1, p. 7.

19 JESUS, Damásio E. de. Direito Penal. 19 ed. São Paulo: Saraiva, 1999. v. 1, p. 7.

${ }^{20}$ NORONHA, E. Magalhães. Direito penal. 34. ed. São Paulo: Saraiva,1999. v. 1, p. 4. causais-explicativas."21 Porém, é ao expor suas considerações sobre o método científico utilizado pelo Direito Penal, que Magalhães Noronha revela o reducionismo da sua ciência:

Seu método é o técnico-jurídico, cujos meios nos levam ao conhecimento preciso e exato da norma. Orienta-nos no estudo das relações jurídicas, na elaboração dos institutos e formulação do sistema. Tal método é de natureza lógico-abstrata, o que bem se compreende, já que, se a norma jurídica tem por conteúdo deveres, para conhecê-los bastam sua consideração e estudo, nada havendo para observar ou experimentar. ${ }^{22}$ (grifo nosso)

Ainda no campo do Direito Penal, outro penalista, Júlio Fabbrini Mirabete se destaca com o seu Manual de Direito Penal que quase atinge a vigésima quinta edição. Com a mesma finalidade de introduzir o aluno leitor no estudo do Direito Penal, o autor apresenta uma série de conceituações extraídas de diversos autores da área:

Do exposto, derivam as definições de Direito Penal que passamos a reproduzir: 'é o conjunto de normas jurídicas que o Estado estabelece para combater o crime, através das penas e medidas de segurança', é 'o conjunto de normas jurídicas que regulam o poder punitivo do Estado, tendo em vista os fatos de natureza criminal e as medidas aplicáveis a quem os pratica' é 'o conjunto de normas que ligam ao crime, como fato, a pena como conseqüência, e disciplinam também as relações jurídicas daí derivadas, para estabelecer a aplicabilidade de medidas de segurança e a tutela do direito de liberdade em face do poder de punir do Estado, é o conjunto de normas e disposições jurídicas que regulam o exercício do poder sancionador e preventivo do Estado, estabelecendo o conceito do crime como pressuposto da ação estatal, assim como a responsabilidade do sujeito ativo, e associando à infração da norma uma pena finalista ou uma medida de segurança ${ }^{23}$ (grifo nosso)

Na mesma esteira dos outros autores, Julio Fabbrini Mirabete conclui que a ciência jurídico-penal é:

uma ciência normativa, pois seu objeto é o estudo da lei, da norma, do direito positivo, como dado fundamental e indiscutível em sua observância obrigatória. Não se preocupa, portanto, com a verificação da gênese do crime, dos

\footnotetext{
${ }^{21}$ NORONHA, E, Magalhães. Direito Penal. 32. ed. São Paulo: Saraiva, 1999. v. 1, p 8.

${ }^{22}$ NORONHA, E, Magalhães. Direito Penal. 32. ed. São Paulo: Saraiva,1999. v. 1, p 8 .

${ }^{23}$ MIRABETE, Julio Fabbrini. Manual de direito penal. 18 a ed, São Paulo: Atlas, 2001. v. 1, p. 23.
} 
fatos que levam à criminalidade ou dos aspectos sociais que podem determinar a prática do ilícito, preocupações próprias das ciências causais explicativas, como a Criminologia, a Sociologia Criminal etc. ${ }^{24}$ (grifo nosso)

Mudando de ramo do Direito, o paradigma dogmático de ciência jurídica continua presente, como por exemplo, nesta citação de José Afonso da Silva, um constitucionalista, sobre o Direito Constitucional:

\begin{abstract}
Podemos defini-lo como - ramo do Direito Público que expõe, interpreta e sistematiza os princípios e normas fundamentais do Estado. Como esses princípios e normas fundamentais do Estado compõem o conteúdo das constituições (Direito Constitucional Objetivo), pode-se afirmar, como faz Pinto Ferreira, que o Direito Constitucional é a ciência positiva das constituições. ${ }^{25}$ (grifo nosso)
\end{abstract}

No mesmo sentido, define André Ramos Tavares: "Pragmaticamente, o Direito constitucional identifica-se como a análise de um conjunto normativo: A Constituição do Estado."26 Ora, reduzir o estudo do Direito Constitucional é excluir todo o elemento político e social que permeia todo o sistema constitucional e é imprescindível a compreensão da própria Constituição.

Quando se trata do direito privado, a situação não é diferente. Os civilistas, que publicam seus Manuais e Cursos de Direito Civil, não fogem ao paradigma dominante. Ao explicitar a trajetória histórica do Direito Civil, Maria Helena Diniz admite que ele, "a partir do século XIX toma um sentido mais estrito para designar as instituições disciplinadas no Código Civil. ${ }^{\text {’7 }}$ Assim, o direito civil, segundo a autora, "regulamenta os direitos e deveres de todas as pessoas, enquanto tais, contendo normas sobre o estado, a capacidade e as relações atinentes à família, às coisas, às obrigações e sucessões."28 (grifo nosso)

Para outro importante civilista, Silvio Rodrigues: "O direito é a norma das ações humanas na vida social,

${ }^{24}$ MIRABETE, Julio Fabbrini. Manual de direito penal. $15^{\mathrm{a}} \mathrm{ed}$, São Paulo: Atlas, 2001. v.1, p 24.

${ }^{25}$ SILVA, José Afonso. Curso de direito constitucional positivo. 19. ed. São Paulo: Malheiros, 2001. p. 34

${ }^{26}$ TAVARES, André Ramos. Curso de direito constitucional. 5. ed. São Paulo: Saraiva, 2007. p. 18.

${ }^{27}$ DINIZ, Maria Helena. Direito civil brasileiro. 18. ed. São Paulo: Saraiva, 2002. p. 45.

${ }^{28}$ DINIZ, Maria Helena. Direito civil brasileiro. 18. ed. São Paulo: Saraiva, 2002. p. 18. estabelecida por uma organização soberana e imposta coativamente à observância de todos." ${ }^{29}$ (grifo nosso)

Dentre os doutrinadores da área do Direito trabalhista, destaca-se a afirmação de Amauri Mascaro do Nascimento:
Direito do trabalho é o ramo da ciência do di- reito que tem por objeto as normas jurídicas que disciplinam as relações de trabalho subor- dinado, determinam os seus sujeitos e as orga- nizações destinadas à proteção desse trabalho, em sua estrutura e atividade. ${ }^{30}$ (grifo nosso)

De outro Manual consagrado nos bancos acadêmicos, destaca-se a opinião de Orlando Gomes e Elson Gottschalk que o:

conteúdo do Direito do Trabalho, não só as regras que regulam o contrato de trabalho, como as prestações deste em linha de fato; as regras que se aplicam a empregados contratados por outrem, mas eventualmente a serviço da empresa, ou que trabalhem sem continuidade; as regras de tutela do trabalho enquanto perdura a prestação; as regras do Direito Coletivo e do Individual; as regras que protegem o trabalhador fora do trabalho, como os Seguros Sociais e os Acidentes de Trabalho; as regras que regulam a organização e o processo administrativo do trabalho, bem como se valoriza a jurisprudência judiciária e administrativa do trabalho, tão importantes na elaboração de nosso Direito" ${ }^{31}$ (grifo nosso)

Por fim, no direito processual, o paradigma epistemológico permanece o mesmo, tanto no Processo Civil quanto no Processo Penal. Seguem citações extraídas de obras de Direito Processual.

Sobre o Direito Processual Civil afirma Humberto Teodoro Junior que "pode ser definido como o ramo da ciência jurídica que trata o complexo das normas reguladoras do exercício da jurisdição civil."32

Por seu turno, o Direito Processual Penal é assim conceituado: "conjunto de normas e princípios que regulam a aplicação jurisdicional do Direito Penal objetivo, a

\footnotetext{
${ }^{29}$ RODRIGUES, Silvio. Direito civil. 32. ed. São Paulo: Saraiva, 2002. v. 1, p. 6.

${ }^{30}$ NASCIMENTO, Amauri Mascaro. Curso de direito do trabalho. 17. ed. São Paulo: Saraiva, 2001. p. 155

${ }^{31}$ GOMES, Orlando; GOTTSCHALK, Elson. Curso de direito do trabalho. 10. ed. Rio de Janeiro: Forense, 1987. 2 v. p. 12.

32 THEODORO JR, Humberto. Curso de direito processual civil. 26. ed. Rio de Janeiro: 1999. v. 1, p. 6.
} 
sistematização dos órgãos de jurisdição e respectivos auxiliares bem como da persecução penal." ${ }^{33}$

Emblemática é a natureza científica atribuída por Julio Fabrini Mirabete ao Direito Processual Penal:

O Direito Processual Penal constitui uma ciência autônoma no campo da dogmática jurídica, uma vez que tem objeto e princípios que lhe são próprios. Sua finalidade é conseguir a realização da pretensão punitiva derivada da prática de um ilícito penal, ou seja, é de aplicar o Direito Penal. Tem, portanto, um caráter instrumental; constitui o meio para fazer atuar o direito material penal, tornando efetiva a função deste de prevenção e repressão das infrações penais. ${ }^{34}$

E continua:

É o Processo Penal uma disciplina normativa, de caráter dogmático. Partindo da norma jurídica, investiga os princípios, organiza os institutos e constrói o sistema. Seu método é o técnico-jurídico, que permite ao jurista extrair de todo o conjunto de regras 'os preceitos aplicáveis a uma situação concreta, não só lhes descobrindo o sentido latente e oculto, como também lhes devolvendo os corolários e consequência. ${ }^{35}$

Como se pode observar, os Manuais utilizados nas diversas disciplinas consideradas profissionalizantes são unânimes ao considerar como objeto de sua ciência a norma jurídica e a aplicação desta norma como sua finalidade última.

Todas as definições aqui apresentadas - conforme citação das fontes bibliográficas- podem ser coletados em livros e em manuais utilizados em sala de aula e em concursos públicos. Aliás, conforme afirma Lênio Strek, geralmente os concursos públicos para as carreiras da magistratura, do Ministério Público, da Advocacia Pública e da Defensoria Pública seguem a mesma linha da sala de aula e dos manuais jurídicos: "trabalham com problemas idealistas/idealizados/objetificantes, com conflitos atomizados, desindexados do mundo da vida, é dizer, descontextualizados das relações sociais."36

${ }^{33}$ TORINHO FILHO, Fernando Costa. processo penal. 18. ed. São Paulo: Saraiva, 1997. v. 1, p. 29.

${ }^{34}$ MIRABETE, Júlio Fabbrini. Processo penal. 7. ed. São Paulo: Atlas, 1996. p. 30

${ }^{35}$ MIRABETE, Júlio Fabbrini. Processo penal. 7. ed. São Paulo: Atlas, 1996. p. 30.

${ }^{36}$ STRECK, Lenio Luiz. Hermenêutica jurídica e $(m)$ crise: uma exploração hermenêutica da construção do direito. 2. ed. Porto Alegre: Livraria do Advogado. 2000. p. 72.
Há que se reconhecer, nesse contexto, como afirma Luís Alberto Warat que existem diferentes instituições como produtoras e reprodutoras do senso comum teórico dos juristas tais como "os parlamentos, os tribunais, as escolas de direito, as associações profissionais e a administração pública." ${ }^{\text {"37 }}$ Porém, para ele, "parece inegável o lugar privilegiado que as escolas de direito ocupam como formadoras de um sistema mais ou menos difuso, pouco explicitado de estereótipos fundantes" do sentido comum teórico dos juristas. ${ }^{38}$

José Eduardo Faria diagnostica o Ensino Jurídico como um ensino em nível do sentido comum teórico dos juristas, na medida em que:

valoriza-se quase que exclusivamente uma abordagem sistemática e lógico-dedutiva, privilegiando-se o princípio da autoridade - isto é, a opinião dos 'preclaros mestres', dos 'insígnes doutores', dos 'notáveis educadores', dos 'doutos colegas', todos muitas vezes citados aos borbotões e usados como pretexto para demonstração de uma erudição sem peso teórico, recheando manuais e livros - isto quando não servindo para engrossar teses acadêmicas de professores pouco criativos e sem inspiração, abrindo caminho para que o 'pedantismo da ligeireza' sirva de critério para o prevalecimento, no âmbito do corpo docente, de um tipo modal de mestre acrítico, burocrático e subserviente aos clichês e estereótipos predominantes entre os juristas de ofício. $^{39}$

É na engrenagem conformadora do senso comum teórico que encontramos os livros de Direito. Manuais de presença obrigatória em qualquer disciplina dogmática que for ministrada e que se limitam à exegese dos textos legais. Na maioria dos casos explica Horácio Wanderlei Rodrigues:

não passam de cópias de cópias de cópias. Os amontoados de citações demonstram a erudição de seus autores e também a sua absoluta falta de criatividade. Quanto mais esquemáticos e donos da verdade, melhor. Não há lugar no ensino do Direito para o aprofundamento de temas e muito menos para a dúvida. ${ }^{40}$

${ }^{37}$ WARAT, Luís Alberto. O Sentido Comum Teórico dos Juristas. In: FARIA, José Eduardo (Org.). A crise do direito numa sociedade em mudança. Brasília: UnB, 1988. p. 39.

${ }^{38}$ WARAT, Luís Alberto. A Produção Crítica do Saber Jurídico. In: PLASTINO, Carlos Alberto.(Org.). Crítica do direito e do estado. Rio de Janeiro: Graal, 1984. p 22.

${ }^{39}$ FARIA, José Eduardo. A reforma do ensino jurídico. Porto Alegre: Sergio Antonio Fabris Editor, 1987. p 47.

${ }^{40}$ RODRIGUES, Horácio Wanderlei. Ensino jurídico e direito alternativo. São Paulo: Acadêmica, 1993. p. 82 
Ora, o uso de manuais pelas faculdades de direito não conseguirá lograr êxito na busca de um bacharel em direito com sólida formação geral, humanística e axiológica, como estabelece o Instituto Nacional de Pesquisas Educacionais Anísio Teixeira - INEP, em seu relatório de 2006. Exige-se do bacharel em direito, além dessas habilidades, capacidade de análise, interpretação e valorização dos fenômenos jurídicos e sociais, aliada a uma postura reflexiva e visão critica que fomente a capacidade e aptidão de aprendizagem autônoma e dinâmica, consoante o disposto no referido relatório.

Verifica-se, pois, que tais habilidades não serão obtidas por meio do emprego de manuais que não suscitam uma visão critica e dialética do aluno sobre a matéria, mas apenas comentam o conteúdo dos códigos, sem suscitar uma discussão aprofundada do tema.

\section{Conclusão}

Em face do exposto acima tem-se que o "sentido comum teórico dos juristas" como o conjunto de crenças, valores e justificativas por meio de disciplinas específicas, legitimadas mediante discursos produzidos pelos órgãos institucionais.

É necessário superar os antigos paradigmas e propiciar o redimensionamento de práticas pedagógicas. Urge a criação de novas concepções metodológicas capazes de atender as necessidades da ciência jurídica.

Como visto acima, a constatação do paradigma epistemológico do ensino jurídico brasileiro é imprescindível para se propor uma reformulação do ensino jurídico, que não deve se limitar como têm ocorrido a mudanças curriculares e legislativas. É necessário, sobretudo, alterar o método de ensino. E essa alteração perpassa inevitavelmente pela mudança na adoção de "manuais" pelas faculdade de direito.

A escolha das obras jurídicas para compor a bibliografia de uma disciplina é imprescindível para o desenvolvimento das habilidades necessárias aos bacharéis em direito na atualidade.

Em uma sociedade globalizada o ensino do direito estar restrito ao uso de manuais é privar o aluno das informações e elementos necessários para enfrentar os desafios impostos por essa sociedade e pelo próprio ordenamento jurídico.

\section{Referências}

CAMPILONGO, Celso. OAB: Ensino Jurídico. In: $O A B$ Ensino Jurídico: diagnósticos, perspectivas e propostas. Brasília: Conselho Federal da OAB, 1996.

FARIA, Adriana Ancona de. "A formação de novas competências: articulação da grade curricular e de metodologias participativas no curso de Direito da GV In: SILVEIRA, Vladmir Oliveira da; COUTO, Monica Bonetti; SANCHES, Samyra Haydêe Dal Farra Naspolini (Org.). Educação jurídica. São Paulo: Saraiva, 2013.

FARIA, José Eduardo. A reforma do ensino jurídico. Porto Alegre: Sergio Antonio Fabris Editor, 1987.

FERRAZ JÚNIOR, Tércio Sampaio. OAB: Ensino Jurídico. In: $O A B$ Ensino Jurídico: diagnósticos, perspectivas e propostas. Brasília: Conselho Federal da OAB, 1996.

FONSECA, Ricardo Marcelo. Introdução teórica à história do direito. Rio de Janeiro: Livraria Freitas Bastos, 2010.

GOMES, Orlando; GOTTSCHALK, Elson. Curso de direito do trabalho. 10. ed. Rio de Janeiro: Forense, 1987. $2 \mathrm{v}$.

JESUS, Damásio E. de. Direito penal. 22 ed. São Paulo: Saraiva, 1999. v. 1.

LYRA FILHO, Roberto. O direito que se ensina errado. Brasília: UnB, Centro Acadêmico de Direito, 1980.

LÔBO, Paulo Luiz Neto. et al. Uma Cartografia dos Problemas. In: $O A B$ Ensino Jurídico: diagnósticos, perspectivas e propostas. Brasília: Conselho Federal da OAB, 1996.

MARQUES NETO, Agostinho Ramalho. A ciência do direito: conceito, objeto, método. 2. ed. Rio de Janeiro: 2001.

MIRABETE, Júlio Fabbrini. Processo penal. 7. ed. São Paulo: Atlas, 1996.

MIRABETE, Julio Fabbrini. Manual de direito penal. 18. ed. São Paulo: Atlas, 2001. v. 1.

NASCIMENTO, Amauri Mascaro. Curso de direito do trabalho. 17. ed. São Paulo: Saraiva, 2001.

NORONHA, E, Magalhães. Direito penal. 34 a ed, São Paulo: Saraiva,1999. v. 1. 
PAGANI, Juliana Ferrari de Oliveira."A pós-graduação stritco sensu em Direito no Brasil: a formação dos professores das disciplinas pedagógicas oferecidas em seus programas" In.: SILVEIRA, Vladmir Oliveira da; COUTO, Monica Bonetti; SANCHES, Samyra Haydêe Dal Farra Naspolini (Org.). Educação jurídica. São Paulo: Saraiva, 2013.

RODRIGUES, Horácio Wanderlei. Novo currículo mínimo dos cursos jurídicos. São Paulo: RT, 1995.

RODRIGUES, Horácio Wanderlei. Ensino jurídico e direito alternativo. São Paulo: Acadêmica, 1993.

RODRIGUES, Silvio. Direito civil. 32. ed. São Paulo: Saraiva, 2002. v. 1.

SILVA, José Afonso. Curso de direito constitucional positivo. 19. ed. São Paulo: Malheiros, 2001.

STRECK, Lenio Luiz. Hermenêutica jurídica $e(m)$ crise: uma exploração hermenêutica da construção do Direito. 2. ed. Porto Alegre: Livraria do Advogado. 2000.
TAVARES, André Ramos. Curso de direito constitucional. 5. ed. São Paulo: Saraiva, 2007.

THEODORO JR, Humberto. Curso de direito processual civil. 26. ed. Rio de Janeiro: 1999. v. 1

TORINHO FILHO, Fernando Costa. Processo Penal. 18. ed. São Paulo: Saraiva, 1997. v. 1.

UNGER, Roberto Mangabeira. Uma nova faculdade de direito no Brasil. Paper apresentado na Fundação Getúlio Vargas como parecer sobre a criação da Escola de Direito de São Paulo/FGV - EDESP, 2001. p. 1-29.

WARAT, Luís Alberto. O sentido comum teórico dos juristas. In: FARIA, José Eduardo (Org). A crise do direito numa sociedade em mudança. Brasília: UnB, 1988.

WARAT, Luís Alberto. A Produção Crítica do Saber Jurídico. In: PLASTINO, Carlos Alberto (Org). Crítica do Direito e do Estado. Rio de Janeiro: Graal, 1984. 


\section{Para publicar na revista Universitas/JUS, acesse $o$ endereço eletrônico www.publicacoesacademicas.uniceub.br.}

Observe as normas de publicação, para facilitar e agilizar o trabalho de edição. 